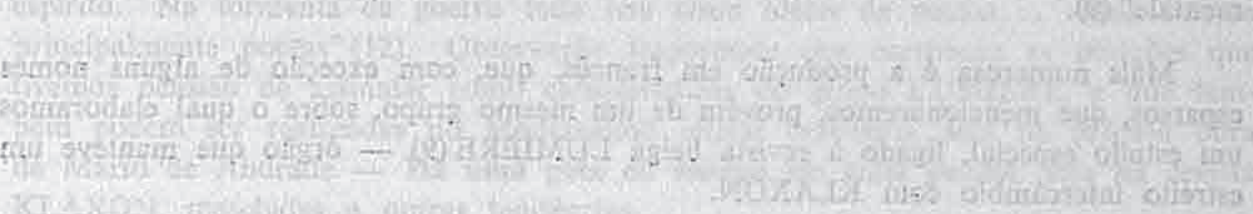

\title{
A COLABORAÇÃO ESTRANGEIRA NA REVISTA KLAXON
}

\section{Cecília de Lara}

Quando realizamos o estudo da matéria da revista literária KLAXON verificamos que junto à produção dos modernistas brasileiros aparecia, a cada número, mais de uma colaboração estrangeira, num total significativo.

Ao todo, dez autores estrangeiros constam do índice remissivo de colaboradores da KLAXON (1). Já o número de colaborações em língua estrangeira é bem maior, pois às vezes um mesmo autor aparece mais de uma vez e também há brasileiros que escrevem em francês. Por outro lado, Antônio Ferro sendo português, usa a língua portuguesa e resta a se considerar o caso de colaboraçōes traduzidas ao português. Assim, segundo o critério lingüístico, há vinte e três colaborações em língua estrangeira: duas em espanhol, quatro em italiano, e as demais em francês. - sendo que em nenhum destes casos consta o nome do tradutor.

Dos brasileiros que escrevem em francês temos dois poemas de Manuel Bandeira: "Bonheur Lyrique" e "Poème" (3), e seis colaborações em prosa e poesia de Sergio Milliet: "Misere", "Voyage", "Visions", "Reverie", "La Guerre" e "Noel" (4).

Em espanhol, dois poemas de Guillermo de Torre assinalam a presença de uma das correntes de vanguarda espanholas - O Ultraismo com os poemas "A1Volante" e "Atmosfera" (5). Um outro autor, Claudius Caligaris, colabora em italiano, com o poema "Só di un treno" e em português com o poema "O meu passado" - que deve ser uma tradução (6). Também em italiano Vin. Ragognetti

(1) Referimo-nos ao indice classificado de colaboracōes e calaboradores que realizamos como parte do estudo da matéria da revista KLAXON, publicado pelo Instituto de Estudos Brasileiros da USP em 1972, v. 19, sob o titulo: KLAXON \& TERRA presentes consideraçōes como complementares a este estudo de IKLAXON.

(2) Há referência à traduçăo francesa da obra TANKAS de Nico Horigoutchi, na revista belga LUMmeRE, que mantinha intercâmbio com KLAXON.

(3) "Bonheur lyrique" apareceu no n.0 3 de KLAXON, p. 3 e "Poème" no n.o 5. D. 8 .

(4) As colaboraçōes de Sérgio Milliet parecem regularmente em quase todos os números de KLAXON: "Miserere" n. 2, p. 32; "Voyage" "र n.0 3, p. 3; "Visions"

(5) "Al Volante" n.o 5, p. 3 e "Atmosfera" n.o 8-9, p. 16.

(6) Vin. Ragognetti colabora no n.0 2, com "Cercare il proprio dominio", p. 8, 9 e no n.0 4, p. 4, com "Danze delle giornate grigie cariocas", 
colabora com dois poemas: "Cercare il proprio dominio" e "La danze delle giornate grigie cariocas" (7). Há, ainda em italiano, de Gaetano Cristaldi a "Égloba sentimentale" (8).

Mais numerosa é a produção em francês, que, com exceção de alguns nomes esparsos, que mencionaremos, provém de um mesmo grupo, sobre o qual elaboramos um estudo especial, ligado à revista belga LUMIERE (9) - órgão que manteve um estreito intercâmbio com KLAXON.

Com a localização deste grupo identificamos alguns dos autores estrangeiros presentes na revista de S. Paulo, mas o resultado mais importante foi, sem dúvida, o de trazer à tona um dos veios das vanguardas européias entre muitos outros canalizados para KLAXON na ocasião. E ficou, também, patente que embora predomine como língua o francês, os autores são belgas e suíços.

Após a realização do estudo das relações KLAXON-LUMIËRE, o acaso permitiu o reencontro com alguns nomes de autores estrangeiros que continuaram mantendo ligações com a cultura brasileira, pois anos depois reaparecem como colaboradores de outra revista de São Paulo: ANHEMBI (10). E o caso de Charles Baudouin e Henri Mugnier. E foi a partir do nome de Henri Mugnier que conseguimos deslindar o ponto de partida das relações do grupo modernista de São Paulo com alguns grupos europeus, como o citado LUMIERE.

Em entrevista, conta Sergio Milliet como foi o contato inicial com algumas dessas figuras na Suíça: "Era estudante de Ciências Econômicas e Sociais. 'Ligara-me a uns rapazes brasileiros que lá mantinham uma pequena revista literária". E prossegue respondendo: "Foi na tal revistazinha em Genebra que comecei a publicar algumas coisas". Noutra resposta esclarece: "Um dia tive a emoção de ser convidado para uma reunião na casa do poeta Henri Mugnier. Passei a colaborar em jornais suíços; em pouvo estava transformado em poeta genebrino. A guerra mundial de 1914 foi outra circunstância que contribuiu para a minha perseverança na literatura." E explica-nos a razão: "E que, então, se reuniam em Saconnex D'Arve, na casa de Charles Baudouin, na época simples 'grande ferido' internado na Suíça, alguns grandes espíritos brilhantes, Romain Rolland, Steffan Zweig, Henri Spiess, Karl Spitteler, Ivan Goll, Jean Violette... Pintores e escultores de nomeada, como Holdler, Vibert Fehr, também apareciam.

"E apareciam também, alguns estudantes, meus companheiros, entre os quais Charles Reber, que o jornalismo conquistou definitivamente" (11).

Sobre a linha do grupo que se reunia em Saconnex D'Arve, mencionado por S. Milliet na mesma entrevista, é importante salientar o sinal das posiçōes de Romain

(8) Crisaaldi colabora com "Egloga sentimentale" no n. 5, p. 8, 9.

5. (9) O estudo do grupo da revista LUMİ̉RE, está publicado em CARAVELLE n. publicada nos anos de 1950 a 1962 . cultura de $\mathbf{S}$. Paulo, dirigida por Paulo Duarte,

(1i) Entrevista a Silveira Peixoto, em Falem os Escritores, Conselho Estadual de Cultura, S. Paulo, 1971, p. 101. Sobre S. Milliet ver, também, o estudo sobre LU. 
Rolland: "O cenáculo caracterizava-se por uma preocupação de humanismo, de serenidade, de universalismo, de objetivismo, que marcou profundamente o meu espírito. Na tormenta da guerra tudo isso eram ideais de poetas... Mas éramos principalmente poetas" (12). Observação importante que corrobora as posiçōes que tivemos ocasião de assinalar como características do grupo LUMIERE, e que também podem ser rastreadas no Modernismo inicial brasileiro, seja na própria obra de Mário de Andrade - Há uma gota de sangue em cada poema, seja na revista KLAXON, mescladas a outras tendências.

Por ocasião da morte de H. Mugnier, em 1957, Sergio Milliet novamente se refere aos primeiros contatos que teve com o autor de Genebra, a partir de 1917: "Foi quando conheci H. Mugnier e os escritores do grupo Jean Violette, entre os quais se encontrava Charles Baudouin, hoje conhecido mundialmente por seus trabalhos psicanalíticos.

"Henri Mugnier gostara de um meu poema e o fizera publicar. Mais tarde foi quem me incentivou a reunir em volume alguns trabalhos. Tornamo-nos desde logo bons amigos e companheiros de todos os dias." (13). O trabalho a que se refere S. Milliet é o livro Par le Sentier. Depois publicou outro, que the deu notoriedade em outros países, Le Départ sous la Pluie, sobre o qual diz, na entrevista citada: "Com esse segundo livro o eco dos meus trabalhos repercutiu em Paris, em Marselha, em Bruxelas".

As palavras de S. Milliet são confirmadas por Henri Mugnier que em ANHEMBI, ao traçar o "Panorama da poesia contemporânea na Suíça Francesa" (14) fala dos grupos literários de 1914 a 1920, sendo que situa Sergio Milliet no grupo de Jean Violette: "Foi no seu grupo - que tomou o nome de grupo La Violette - que S. Milliet quando estudante na Universidade de Genebra, fez suas primeiras armas e sofreu as primeiras críticas dos seus poemas em francês, e foi também sob a égide desse grupo que ele publicou o seu primeiro volume de poemas que tive a honra de prefaciar e que iniciou, em suma, a brilhante carreira que devia ser a sua".

Logo, não há problema quanto à explicação da presença de Mugnier em KLAXON - pois isto foi devido ao seu relacionamento pessoal com Sergio Milliet. $\mathrm{Na}$ revista a presença de $\mathrm{H}$. Mugnier se assinala através de uma nota que se refere a uma opinião que proferiu no jornal francês que aqui circulava: "No Messager de São Paulo de 8 de abril o sr. Henri Mugnier assina um artigo sobre o "Modernismo', cheio de bom senso e reflexão". Mas, refuta KLAXON em seguida: "Ao doloroso ceticismo, com que o sr. Mugnier termina o seu belo artigo, respondemos: A arte para o artista legítimo é como o ar e o pão: elemento de vida".(15).

Há, também, colaboração direta de Mugnier em KLAXON: o poema em francês "L'Arbre" com traços que lembram as posiçōes de LUMIERE e do grupo suíço de

(12) IDEM, ibidem.

(13) S. M. (Sergio Milliet). ANHFMBRI, Maio de 1957, n.o 78, v. XXVI.

(14) "Conhecimento da Suiça Francesa", ANHFMBI, Maio de 1951, n. 6 , v. II.

(15) KIAXON n.० 1, D. 15, "Luzes e Refraçōes". 
Charles Baudouin, e uma crítica, em português: "Exposição Hermman" (16). Quando a revista encerrou suas atividades em 1923, com o número duplo 8-9, publicou a lista completa de colaboradores do Brasil e de fora. E o nome de Henri Mugnier aparece entre os franceses. Ao reecontrarmos o seu nome como colaborador constante de ANHEMBI de 1951 a 1957, pudemos esclarecer melhor alguns fatos da época do início do Modernismo. Em ANHEMBI Mugnier aparece como uma espécie de correspondente estrangeiro, falando de aspectos diversos da Suíça. "Conhecimento da Suíça Francesa" foi publicado em duas partes. Trata, ainda, da "Arte Dramática na Suíça Francesa" (17) e em outra ocasião escreve sobre um poeta que marcou sua geração e que também foi importante no Modernismo brasileiro, o belga Verhagen, morto em acidente em 1916: "Sobre uma geração - Verharen e nós" (18). Na forma de noticiário é a "Crônica de Genebra" (19). Em visita ao Brasil, em 1953, novamente fatos novos são trazidos à baila. Recordam que Mugnier tinha estado no Brasil, na ocasiāo da Semana de Arte Moderna, e referem-se a uma obra Choix de poèmes que tinha sido publicada com prefácio de Charles Baudouin (20). S. Milliet fala desta obra, que reunia poemas de 1913 a 1952; a trajetória vital do autor se refaz, e então o vemos dimensionado como pessoa: "Com a viagem ao Brasil, a dura existência de caixeiro viajante pelas cidades do interior, a solidão, a saudade, essa poesia assumiu um tom mais amargo". E continua: "Mugnier abandona o comércio, volta à poesia, escreve para o teatro, e para o rádio, publica vários volumes de prosa e verso...".

Uma notícia sem assinatura também se refere a essa segunda visita de $H$. Mugnier ao Brasil: "Depois de uma ausência de trinta e dois anos voltou a visitar - Brasil o ilustre poeta e escritor Henri Mugnier, conhecido há muitos anos em Genebra, como o maior amigo de nosso país, na Suíça. Os leitores de ANHEMBI conhecem bem H. Mugnier, através de artigos aqui publicados com a sua assinatura. Escritor, jornalista, teatrólogo, poeta, Henri Mugnier veio rever os amigos brasileiros depois de uma ausência, como dissemos, de mais de seis lustros" (21).

Tal fato se deu em 1953 e em maio de 1957 novamente o nome de H. Mugnier vem à baila em ANHEMBI, agora noticiando sua morte. S. Milliet, nessa ocasião, recorda passagens de seu relacionamento com Mugnier na Suíça e diz que, ao partir da Europa, em 1921, sugeriu ao poeta que viesse tentar a vida no Brasil. E foi o que aconteceu, pois em 1922 Mugnier se achava em São Paulo: "Durante os dois anos que aqui esteve participou da vida literária freqüentando a casa de Mário de Andrade e colaborando com o grupo paulista na Semana da Arte Moderna". E informa como voltou a visitar O Brasil anos depois: "Passaram-se anos até que um dia, graças à insistência de Ribeiro Couto, foi o nosso poeta convidado a rever o Brasil. Andou pelo Rio e S. Paulo, encontrou velhos amigos

(16) "L'Arbre" está no n.० 4, p. 5 e "Exposiçáo Hermman" no n.o 1, p. 14-15. "1 (17) "A arte dramática na Suiça Francesa". ANHEMBI, Outubro de 1951 n.o" 11 , (18) ANHEMIBI, Agosto de 1952, n. 21 , v. VIII, p. 213.

(19) Noticíario publicado em Anhembi, ns. 17 e 18, de Abril e Malo de 1952, ps.

359 e 576 , respectivamente.

(20) S. Milliet fala de Mugnier no no 34 de ANHFMBI, Setembro de 1952, p. 141.

(21) A noticia sem assinatura é de Outubro de 1853, n.o $35, \mathrm{p}$. 336 . 1952 , p. 
e retornou a Genebra para continuar a admirável e generosa propaganda de nossa terra, que já vinha fazendo há tempos. Pelo rádio e pelos jornais não perdia a oportunidade de dizer o que vira. E ao morrer agora, com 67 anos, preparava uma série de artigos sobre a moderna poesia brasileira". S. Milliet oferece uma amostra da poesia de Mugnier e conclui: "Mas não foi apenas um poeta. Escreveu romances igualmente e várias peças de teatro, tendo obtido em 1952 o prêmio dos críticos de arte dramática.

"Interessado ultimamente em radiodifusão escreveu numerosos 'Schetches' aproveitando sempre, como cenário, a paisagem brasileira" (22). Dados que complementam o quadro da identificação de mais um colaborador estrangeiro de KLAXON, cuja importância primordial foi a ter sido a ponte de ligação entre Sergio Milliet e grupos europeus - o que permitiu a canalização para KLAXON de autores estrangeiros e mesmo de todo um grupo, como o citado LUMIËRE. Além disso é digno de nota 0 fruto mais tardio desses relacionamentos, pois alguns tiveram continuidade. No caso de Mugnier ainda vale a pena pensar-se em investigar a outra face, ou seja, a divulgação da cultura brasileira que empreendeu por muitos anos em Genebra.

Mas, resta ainda, no caso, observar que sem nenhum esforço foi se esboçando como destacado o papel de Sergio Milliet, nesta fase de implantação do Modernismo - pois grande parte da colaboração estrangeira veio por seu intermédio, além da contribuição direta que ofereceu como poeta, testemunhando em KLAXON vários aspectos das pesquisas em poesia, sobretudo no que se refere à técnica de composição. A exploração de aspectos visuais, com a valorização do espaço e dos tipos de letras ressaltam em seus poemas, de indiscutível sabor de renovação, mesmo entre a contribuição estrangeira que convergiu para KLAXON.

Sobre este aspecto temos o que diz Péricles Eugênio da Silva Ramos: "Seus poemas aproveitam a falta de pontuação cubista, adotada pelo futurismo, e eram, como superposição, técnica analógica e aproveitamento dos princípios de simultaneidade, dos mais avançados que se escreveram na época em nosso meio, a princípio em francês, depois em português" (23).

Outro colaborador de KLAXON que pertencia às rodas suíças que freqüentou Sergio Milliet foi Charles Baudouin. Conforme verificamos ao estudarmos LUMIËRE, foi também através de Charles Baudouin que Sergio Milliet se relacionou com Roger Avermaete, diretor do grupo belga (24). E o nome de Charles Baudouin reaparecerá mais de uma vez ligado à cultura brasileira, seja pela repercussão de suas obras entre os modernistas seja, anos depois, como colaborador de ANHEMBI (25).

(22) ANHEMBI, Maio de 1957, n. ${ }^{\circ} 78$, v. XXVI.

(23) Na obra Do Barroco ao Modernismo, Conselho Estadual de Cultura, S. Paulo, 1968, D. 242. Também sobre S. Milliet ver de Péricles E. da Silva Ramos: Sergio Militiet $e$ Modernismo. Revista do Instituto de Estudos Brasileiros da USP, n. ${ }^{\circ}$, p. $47-64,1968$.

(24) Ver nota (8). 
Por ocasiáo de sua segunda visita ao Brasil, Mugnier proferiu uma palestra que despertou curiosidade na época, pois tratava do "poeta" Charles Baudouin. Houve até um comentário alusivo ao fato em ANHEMBI: "Charles Baudouin, nosso colaborador, é o célebre psicanalista de Genebra, conhecidíssimo pelos seus profundos trabalhos sobre psicologia, notadamente La Psychanalyse de L'Art, L'Âme et L'Áction, La Force en Nous, Introduction à l'analyse des rêves, Psychanalyse de Victor Hugo e outros notáveis trabalhos. H. Mugnier estudou o psicólogo através de uma face pouco conhecida, isto é, Baudouin como excelente poeta que é" (26). Isto foi dito 30 anos depois da participação de Ch. Baudoin em KLAXON, onde seu nome é justamente valorizado como poeta, merecendo resenha de Mário de Andrade. Sobre o livro de Baudouin Miracle de Vivre Mário de Andrade profere juízos que hesitam em classificar como modernos versos presos à subjetividade do autor. Isto se explica no momento vivido pelo Modernismo brasileiro, no qual se via com desconfiança o intimismo, o subjetivismo na poesia, por se assemelhar a traços simbolistas (chamado de "penumbrismo"), condenado como forma a ser desprezada entre manifestações de modernidade, preocupadas com aspectos da realidade objetiva, do mundo moderno, do progresso, da civilização. A mesma hesitação experimenta Mário de Andrade ante os Epigramas Irônicos e Sentimentais de Ronald de Carvalho, nos quais reconhece, enfim, modernidade, apesar de se prender mais aos aspectos interiores do poeta, e não ao mundo que o cerca (27). Resenhas que assinalamos como importantes em KLAXON por se ligarem diretamente às concepçōes sobre Modernismo, na época. Mas, no caso de Baudouin, o fragmento em prosa que também publicou em KLAXON nos revela que sua preocupação com o mundo subjetivo era, já, antecipação de uma das correntes mais fecundas das Vanguardas - o Surrealismo, pois a pesquisa no mundo interior, a preocupação com os mecanismos da memória e suas associações, que evocam o mundo da infância fundindo espaço e tempo numa mesma imagem e numa mesma emoção-múltipla e complexa - denotam no Baudouin que se interessava pela literatura o futuro psicanalista, que acabará abandonando as trilhas da poesia (28).

Mas, a colaboração estrangeira em KLAXON não se reduz aos grupos e pessoas das relaçōes de Sergio Milliet - embora tenham sido estes realmente de importância muito grande. Há, ainda as colaborações em italiano, espanhol e uma do português Antonio Ferro.

Dos italianos um escapou a nossa identificação: Gaetano Gristaldi - pois nada encontramos sobre ele. Já o nome de. Vin. Ragognetti reaparece como colaborador

(25) Feres, Nites - Leituras em Francês de Mário de Andrade, IFB, USP, 1969, 12 v. 12 entre outros aponta o nome de Cr. Baudouin, cuja obra marginais de Mário de PArt, publicada em 1929, Paris, ed. Alcan, traz anotaçoes marginais de Mario de
Andrade. Este exemplar se encontra na biblioteca do IFB da USP, no acervo de

(26) Ver nota (21), que também se refere a Baudouin.

(27) Ch. Baoudouin publicou em KLAXON dois poemas: "A toi qui que tu sois" n. 1, p. 4 e "Solitudes d'etolles" n. 4, p. 8, 9. A resenha $M$. de Andrade sobre Mirade de Vivre apareceu em KLAXON n. 5, p. 11 e sobre $R$. de Carvalho no n.0 7. p. 14, 15

(28) A única colaboraçăo em prosa de Ch. Baudouin Premiers tmois, publicada em KLAXXN n.0 8-9, p. 25-26. 
de NOVISSIMA (29) e o acaso nos revelou que seu nome esteve ligado à imprensa italiana em São Paulo. Logo, tratava-se de italiano radicado no Brasil, que já em 1912 dirigia um periódico juntamente com J. Elias Magalhães, ROSA D'AMOR, em italiano e português, que teve início em junho do ano de 1912 (30). Novamente nos deparamos com o nome de Vincenzo Ragognetti em abril de 1914, quando aparece como diretor de uma nova publicação periódica - Si Puó? de caráter humorístico, em italiano. Um mensário ilustrado, fundado também por Ragonetti, II Moscone, teve vida longa, pois iniciou-se em 1925 e ao atingir o número $650 \mathrm{em}$ 1941 passou a chamar-se 0 Moscardo, sendo então redigido inteiramente em português. (31).

Outro autor que colaborou em italiano foi Caligaris, que se assinava Claudius Caligaris, mas na realidade se chama Antonio Caligaris e reside atualmente em Milão. Recentemente, em carta, rememorou sua estada em São Paulo há 50 anos, e seus contatos com o grupo modernista. Lembra detalhes como o local da redação de KLAXON, as reuniōes na casa de Mário de Andrade, e outros nomes significativos do movimento, com os quais teve contacto na época. Diz que teve alguns poemas divulgados por Menotti Del Picchia e na ocasião cogitou-se de uma edição de sua poesia que seria feita por Monteiro Lobato. (32). Em carta de Mário de Andrade a Sérgio Milliet, divulgada por Paulo Duarte (33), há uma referência a este autor e uma nota explica que se tratava de um grego de passagem por São Paulo, que teve participação na Semana.

Dos demais colaboradores, há um cuja importância já foi devidamente assinalada em estudo específico sobre a revista ESPRIT NOUVEAU. Trata-se de Nicolas Baudouin, que colabora com um ensaio em KLAXON sobre técnica de composição de poesia: "La moderne poésie a-t-elle bésoin d'une nouvelle technique?"(34). Em KLAXON menciona-se ainda que dirigia a revista La Vie des Lettres e um trecho de uma colaboração sua, transcrito em KLAXON, foi uma das pistas que levaram à investigação das relações da revista francesa Esprit Nouveau e a gênese do pensamento estético de Mário de Andrade. (35).

Os poemas em espanhol, de Guillermo de Torre, trazem às páginas de KLAXON a presença de uma corrente de Vanguarda espanhola o Ultraismo. Segundo o poeta - que era também crítico e historiador do movimento - o Ultraismo buscava a

(29) "Os três autores mais populares da moderna literatura italiana", NOVIS-

(30) NOBRE, Freitas, HISTORIA DA IMPRENSA FM S. PAULO. Ed. L,eia. Săo
(1950, p. 216 . Paulo, 1950, D. 216

(31) IDEM, ibidem - D. 219, 228 e 57, respectivamente.

(32) Temos em nosso poder cópia em xerox de carta enviada a Prof.a Luciana Steggano Picchio, que nos foi oferecida por Carlos Augusto Calil, que por sua vez a obteve de Alexandre Eulálio.

(33) Carta publicada em Mário de Andrade por éle mesmo, Đdart, São Paulo, 1971, p. 286, datada de Março ou Abril de 1923 . Ver nota de rodapé.

(34) Ensaio que propōe o "lirismo trilateral", valorizando o cinema, a exploraçāo de aspectos visutais, para realizar o "poema sinótico" que busca a visăo total. KLA XON, n.0 8-9, D. 22-23.

(35) GREMBCKI, Maria Helena - Mário de Andrade e LEsprit Nouveau, Instituto de Estudos Brasileiros, USP, S. Paulo, 1969, v. II. 
a "reintegração lírica e introdução de uma nova temática" (36). Os meios utilizados eram a valorização da imagem e da metáfora, supressão do anedótico, do narrativo, e efusão retórica; a "recusa ao material, só aceito em seu enviés irônico, impura e deliberadamente mesclado ao moderno, nunca visto de um modo direto mas como cruzamento de sensações"; a ruptura da continuidade do discurso lógico, dando relevo às percepçōes fragmentárias, para manter a pureza do fluxo lírico. Para a poesia reclama, em texto escrito na década de 20 , a síntese, a simultaneidade, a supressão da rima, a liberdade rítmica, a quebra da cadeia sintática, supressão da pontuação substituída pelo espaço e alinhamento quebrado Despreza os recursos auditivos para valorizar os visuais, plásticos; fugindo da temática subjetiva toma da vida moderna os ângulos que se caracterizam pelo supreendente. Como se observa, pontos de vista que coincidem com posiçōes teóricas e realizações do Modernismo brasileiro, presentes em KLAXON. Aspirações e buscas comuns, que se constam nas diferentes manifestações de Vanguarda em cada país, sem implicar necessariamente em influência Outro crítico (37) dirá do Ultraísmo: "Abandono do decorativismo "modernista" (38) e do elemento anedótico, musical, e motivo, e emotivo, e instauração de uma poesia essencialmente metafórica e inspirada nos temas mais dinâmicos e esportivos do mundo moderno".

Os dois poemas de G. de Torre em KLAXON concretizam bem essas linhas. E traços semelhantes estão presentes em colaboraçóes de brasileiros, como Luiz Aranha em "Crepúsculo" e "Aeroplano", Carlos A. de Araujo (Tácito de Almeida) em "Tempestade" e "A mesma tempestade", e o "o Poema abúlico" de Mário de Andrade que, de certa forma, dentro de concepçōes semelhantes, realizam a transfiguração da realidade vista em seus ângulos surpreendentes e mutáveis, às vêzes mais próximas aos processos surrealistas, como a composição de Joseph Billiet, "Paysage" única no gênero entre as de língua francesa (35).

Antonio Ferro, autor português ligado à revista Orfeu, cuja visita ao Brasil foi registrada nas páginas de KLAXON (40), colaborou com um fragmento que

(36) TORRE, G. - Historia de las literturas de vanguardia. Guadarra, Madrid, 1971, p. 314. No acervo de Mário de Andrade do IEB, há uma obra de G. de Torre, HELICES, com a dedicatória: "A los camaradas de KLAXON. Con la simpatía confraternal de Guillermo de Torre", datada de 03/11/1923. Coletanea de poemas de 1918 e 1929, na qual ressalta, de maneira crescente, o uso estético da distribuiçáo da palavras sseguem a curvatura, acompanhando a sugestáo do significado. Na parte palavras sseguem a curvatura, "Palabras en liberdad" sinais matemáticos substituem os nexos de ligaçăo e pontuação. Dentro deste livro encontramos um recorte de colaboraça de G. de Torre em LUMIISRE: o poema cabaret, publicado na revista belga em 15/02/1922, mostrando mais um ponto de contacto entre os grupos de Vanguarda.

Mário de Andrade trocou cartas com G. de Torre, mantendo um relacionamento que se prolongou no tempo. (Acervo de M. de A, documentaçáo).

que se prolongou no tempo. (Acervo de M. de A, documentaçalo). ed. Vicens Vives, Barcelona, 1962, p. 627. (38) Aqui se deve entender "modernista" como Parnasiano e Simbolista, pois se trata de países de língua espanhola.

(39) Ver indice remissivo de colaboradores e colaboraçōes, citado em nota (1).

(40) O Jornal do Comércio, ediçáo de S. Paulo, registra a presença de Antonio Ferro em S. Paulo na década de 20 . Assim, a 8 de Novembro noticia a recepçáo a Antonio Ferro no Automóvel Clube, e fala de uma peça de teatro, Mar Alto, que marcaria o inicio do teatro realis-moderno. Logo maís se anuncia a representação de Mar Airo para 18 de Novembro de 1922 . E a 19 do mesmo mês, um crítico que 
tivemos ocasiäo de estudar, como parte integrante da matéria de KLAXON (41), Com características de manifesto tem a linguagem violenta herdada do Futurismo: "Os livros são cemitérios, sâo fantasmas de tinta", "O nosso teatro é um museu", etc. Linguagem vigorosa, de teor expressionista e surrealista, traduzindo estados de exaltação, Embora em português, significa a presença de aspectos europeus do modernismo - daí sua importância.

Com estas considerações tivemos o intuito de complementar a identificação de colaboradores estrangeiros presentes em KLAXON, que trouxeram, concretamente, contribuições de manifestações de Vanguarda de outras partes do mundo. Quanto ao estudo mais detalhado das colaborações $\mathrm{cm} \mathrm{si,} \mathrm{e} \mathrm{quanto} \mathrm{à} \mathrm{avaliação} \mathrm{de}$ seu significado, acreditamos que só possa ser feito no contexto, sem separar-se do conjunto da matéria da revista KLAXON. Foi o que afirmamos ao considerar esse fato, em trabalho anterior, pois constatamos que o critério linguístico ou de nacionalidade não justificaria estudos à parte.

No contexto da revista KLAXON a presença desses colaboradores de outros países tinha várias funções, sendo a mais importante a de abertura, canalizando para - Brasil várias facetas do pensamento e da prođução estética mundial. Por outró lado desejando ser "internacionalista' KLAXON se preocupa, um pouco ingênuamente, em aparentar uma feição realmente internacional, pelo uso de várias línguas, pela menção contínua a nomes, grupos, publicações estrangeiras, coerente com a posição polêmica ante a crítica tradicional, obrigando-a a atualizar-se quanto ao que se realizava fora. E, por outro lado, procurava um apoio às suas realizações mais discutidas, já que se inseriam em um todo mais amplo, que eram as experiências de Vanguarda em todo 0 mundo.

Não se pode negar que tenha havido colaboraçōes estrangeiras significativas em si - como é o caso de todo o grupo de LUMIERE, e o de outros autores avulsos. Mas, não se pode, também, ignorar que muitas dessas colaboraçōes foram fruto da presença ocasional de certos autores em São Paulo e por isso não apresentam verdadeiro intercâmbio artístico entre países. A colaboração em italiano se revelou desta natureza, pois tanto Caligaris como Ragonetti estavam em São Paulo: um, de passagem, outro fixado, exercendo atividades jornalísticas. Logo, o relacionamento com a literatura italiana ou grupos italianos não existiu efetivamente. Nem houve real intercâmbio entre os dois países.

se assina B., elogla a peça. Há referência a conferências: $A$ arte de bem morrer, a 3 de dezembro e uma nota assinada FPP refere-se a A idade do jazz, outra palestra do intelectual portugues, que aqui esteve como autor e ator de teatro, com sua mulher Fernanda de Castro Ferro. A 21 de janeiro noticia se a partida de Antonio Ferro para o Rio, e no dia 23 sai uma nota sobre seu embarque. Fala-se também do prefácio de A. Ferro para o livro de Francisco Lagreca-Apologia da Arte Moderna, a 3 de fevereiro de 1923 . E de 27 de setembro de 1922 temos um artigo de Oswalc de Andrade: "De Flaubert a Antonio Ferro". Logo, o grupo de KLAXON pode usufruir do contacto com o futurista português que esteve na ocasiáo no Brasil. grupo de KLA

(41) "Nós - publicado em KLAXON, n.0 3. Ver referência a A. Ferro na p.

128, do estudo citado em nota (1). 
Quanto a Guillermo de Torre e Antonio Ferro, outro 6 o significado da colaboração de ambos, pois embora apareçam como nomes isolados eram figuras representativas em seus países e realmente sua colaboração canalizou para KLAXON tendências importantes para uma visão de modalidades diversas das vanguardas.

Já a pessoa de H. Mugnier ganhou relevo pela dimensão que tomou seu relacionamento pessoal com Sergio Milliet e pelos resultados provenientes dese contacto. E a representação européia conjunta mais significativa em si, a do grupo LUMIERE, por sua vez não oferece muito em termos de renovação técnica, através das produçóes em prosa e verso. Na realidade a poesia de $\mathrm{S}$. Milliet é neste aspecto muito mais representativa. Mas, por outro lado, o grupo LUMIERE deixa a marca de um estado de espírito europeu de após-guerra, de certa forma também presente nos primeiros anos de nosso Modernismo. E há aspectos que consideramos importantes, como algumas experiências de tipo surrealista, na prosa, que merecem consideração especial, em conjunto com a colaboração dos brasileiros, pela estreita ligação que mantêm entre si.

Esta tentativa de esmiuçar um pouco melhor o aspecto da colaboração estrangeira não muda em nada aquela feição que KLAXON se atribuiu e efetivamente alcançou na prática: o ecletismo, a multiplicidade, que não permite que se estabeleça linha rígida de interpretação. Assim, saem reforçados os objetivos iniciais de KLAXON, realmente fundamentados no esforço de atualização quanto ao que se realizava fora, no intuito de proporcionar abertura aos artistas, critícos e públicos brasileiros. Convém salientar um aspecto, que parece de relevo: ante toda a contribuição canalizada de fora, KLAXON sabe manter seu próprio papel, sem atitude servil, de supervalorização ou imitação. 0 que busca é o aproveitamento de outras experiências paralelas, já que havia outros empenhados em tarefas semelhantes.

A idéia que se configurará claramente, nas etapas posteriores do movimento, de preocupação com a criação de uma arte brasileira, de uma cultura brasileira, retomando linhas essenciais de outros momentos históricos - no Modernismo surge livre de compromissos, pois o empenho se dá mais na direção da "assimilação" das contribuições estrangeiras, numa atitude de "deglutição", que se definirá na tomada de posição consciente que se denominará "antropafágica", e que, no entanto, está já implícita nestes momentos iniciais do Movimento. 